\title{
Unintended Pregnancy in Ethiopia: Community Based Cross-Sectional Study
}

\author{
Kidest Getu Melese, ${ }^{1}$ Mignote Hailu Gebrie, ${ }^{2}$ \\ Martha Berta Badi, ${ }^{3}$ and Wubalem Fekadu Mersha ${ }^{4}$ \\ ${ }^{1}$ Department of Midwifery, College of Health Sciences and Medicine, Wolaita Sodo University, Wolaita Sodo, Ethiopia \\ ${ }^{2}$ Department of Nursing, College of Medicine and Health Sciences, University of Gondar, Gondar, Ethiopia \\ ${ }^{3}$ Department of Midwifery, College of Medicine and Health Sciences, University of Gondar, Gondar, Ethiopia \\ ${ }^{4}$ Department of Psychiatry, College of Health Sciences and Medicine, Bahir Dar University, Bahir Dar, Ethiopia
}

Correspondence should be addressed to Kidest Getu Melese; kidestgetu2006@gmail.com

Received 8 May 2016; Accepted 4 August 2016

Academic Editor: Enrique Hernandez

Copyright (C) 2016 Kidest Getu Melese et al. This is an open access article distributed under the Creative Commons Attribution License, which permits unrestricted use, distribution, and reproduction in any medium, provided the original work is properly cited.

\begin{abstract}
Introduction. Unintended pregnancy is defined as a pregnancy which is a sum of mistimed pregnancy (pregnancy wanted at a later time) and unwanted pregnancy (pregnancy which is not wanted at all). Unintended pregnancy is a global public health problem and its sequels are major causes for maternal and neonatal morbidity and mortality with its effect to maternal metal illness as well. Objective. To determine the prevalence and associated factors of unintended pregnancy in Debre Birhan town, northeast of Ethiopia, in 2014. Method. Community based cross-sectional study and questionnaire developed from Ethiopian demographic health survey 2011. Participants were 690 currently pregnant mothers. Association of unintended pregnancy with factors was measured with bivariate and multivariate logistic regressions. Result. In this study unintended pregnancy is found to be $23.5 \%$. Being formerly married and never married, distance to the nearest health facility $>80$ minutes, gravidity $>5,1-2$ parity, and partner disagreement on desired number of children are the variables significantly associated with unintended pregnancy. Conclusion. Significant proportion of unintended pregnancy is found in the study area. To minimize unintended pregnancy concerned bodies should work on the identified factors, so we can minimize maternal and neonatal morbidity and mortality and keep the health of the family specifically and country in general.
\end{abstract}

\section{Background}

Unintended pregnancy is defined as pregnancy, which admits either mistimed or unwanted pregnancy $[1,2]$. It is a major global public health problem with bad complication for a mother, a child, a family, a society, and a country as a whole $[1,3-6]$. Unintended pregnancy has direct relation with poor utilization of maternal health care services. Researches relate unintended pregnancy with poor antenatal care utilization, which is a risk factor for unfavorable pregnancy outcome and maternal morbidity and mortality [7-9]. In addition unintended pregnancy results in unsafe abortion, which is the other main cause of maternal mortality and morbidity. Nearly 80,000 mothers die per year because of unsafe abortion and almost 95\% of deaths happen in developing countries [10].
Unintended pregnant women will have low physical and mental health, low self-care, poor health, high level of substance addiction, and depression during pregnancy $[3,11,12]$. Besides, fetus will be delivered by unskilled attendant, delivered as low birth weight, increased rate of hospitalization, and poor growth and inadequate immunization adversely leads to maternal and child death $[2,4]$.

In 2012 worldwide 80 million mothers had unintended pregnancy [13]. Regionally, in more developed regions it is revealed to be 42 per 1000 women. In less developed regions from 1000 pregnancies 57 of them were unintended and the pregnancies end up with unplanned birth, abortion, and miscarriage.

Unintended pregnancy is 36 percent higher in developing country than developed country. In Africa from a total of 49.1 
million pregnancies, 39\% were unintended pregnancy [14]. In Ethiopia according to Ethiopian Demographic Health Survey (EDHS) 2011, the percentage of unwanted births decreased (17\% in 2000 to $9 \%$ in 2011). However the percentage of pregnancy wanted later does not show improvement (1920\%) [15].

Major factors influencing unintended pregnancy are young or old age, low maternal education, unmarried marital status, low income, high parity and gravidity, long estimated time to walk to the nearest health facility, and ever use of family planning (FP) [5, 16-20].

Unintended pregnancy problems and complications are vast. However, evidences and literatures on the problem are limited. Therefore, this paper determines the proportion and associated factors of unintended pregnancy among currently pregnant women in Ethiopia.

\section{Methods}

Community based cross-sectional study was carried out in northeast, located $130 \mathrm{~km}$ northeast of capital city of Ethiopia, Addis Ababa. Six hundred ninety-seven currently pregnant women in study area were included in the study where stratified cluster sampling technique was used to select the study participants.

Pretested and structured interviewer administered questionnaire, which is adopted from EDHS (Ethiopian Demographic Health Survey), were used to assess pregnancy intention. Participants were considered as having unintended pregnancy if they report their current pregnancy as either mistimed or unwanted at the time of conception.

There were a total of 17 questions which is first prepared in English and then translated to local language Amharic and then translated back to English for consistency that contains three parts which assesses the sociodemographic and economic status including age, residence, marital status, education, occupation, estimated time to walk to the nearest health facility, and income. Reproductive variables include gravidity, parity, ideal number of child, and partner desire for a child. Contraceptive characteristics assess ever use of family planning. To assess pregnancy intention mothers were asked a question for the current pregnancy: when you got pregnant did you want to get pregnant at the time? Pregnancy is taken as intended if the response is yes. If no, to determine mistimed and unwanted pregnancy, did you want to wait until later or did you not want later any more children?

Foremost data completeness was checked manually, coded, entered, and analyzed into SPSS version 20. Tables 1 and 2 and frequency were used to report the descriptive result, since the dependent variable is categorical binary and multiple logistic regressions were equipped to identify associated factors of unintended pregnancy. In binary logistic regression variables with $P$ value $\leq 0.2$ were transferred to multiple logistic regressions to adjust the effect of confounders and to distinguish the associated factors. To determine the significance, odds ratio with confidence interval $95 \%$ and $P$ value $\leq$ 0.05 was used.
TABLE 1: Sociodemographic and economic characteristics of participants $(n=690)$.

\begin{tabular}{|c|c|c|}
\hline Characteristics & Frequency & Percentage \\
\hline \multicolumn{3}{|l|}{ Age } \\
\hline$\leq 24$ & 112 & 16.2 \\
\hline $25-34$ & 465 & 67.4 \\
\hline$\geq 35$ & 113 & 16.4 \\
\hline \multicolumn{3}{|l|}{ Residence } \\
\hline Urban & 466 & 67.5 \\
\hline Rural & 224 & 32.5 \\
\hline \multicolumn{3}{|l|}{ Marital status } \\
\hline Currently married & 523 & 75.8 \\
\hline Formerly married* & 76 & 11.0 \\
\hline Never married & 91 & 13.2 \\
\hline \multicolumn{3}{|l|}{ Education level } \\
\hline Tertiary & 290 & 42.0 \\
\hline Secondary & 208 & 30.1 \\
\hline Primary & 113 & 16.4 \\
\hline No education & 79 & 11.4 \\
\hline \multicolumn{3}{|c|}{ Monthly income in United States dollar } \\
\hline$\geq 68.66$ & 456 & 66.1 \\
\hline $45.79-68.62$ & 125 & 18.1 \\
\hline $22.92-45.75$ & 76 & 11.0 \\
\hline$\leq 22.87$ & 33 & 4.8 \\
\hline \multicolumn{3}{|l|}{ Occupation } \\
\hline Government employee & 238 & 34.5 \\
\hline Private employee & 19 & 2.8 \\
\hline Farmer & 133 & 19.3 \\
\hline Merchant & 89 & 12.9 \\
\hline Daily labor & 85 & 12.3 \\
\hline Student & 32 & 4.6 \\
\hline Housewife & 94 & 13.6 \\
\hline \multicolumn{3}{|c|}{ Time to walk to the nearest health facility } \\
\hline$<40$ minutes & 547 & 79.3 \\
\hline 40-79 minutes & 76 & 11.0 \\
\hline$>80$ minutes & 67 & 9.7 \\
\hline
\end{tabular}

Formerly married ${ }^{*}$ : divorced, widowed, and separated.

1 Ethiopian birr $=0.045746$ United States dollar.

2.1. Ethical Consideration. Ethical clearance was obtained from the Ethical Review Committee of University of Gondar. Permission letter was obtained from local health department. For all study participants information was given about the study before the data collection on its possible risk, benefit, confidentiality, privacy, its voluntary activity, right of withdrawal, and the time the questionnaire will take and then verbal consent was obtained. Privacy and confidentiality were kept; name of the mother was not asked and recorded.

\section{Result and Discussion}

3.1. Sociodemographic and Economic Characteristics. A total of 697 participants were interviewed; of them 465 (67.4\%) were in the age group of 25-34. Four hundred sixty-six 
TABLE 2: Reproductive and contraceptive utilization characteristics of participants $(n=690)$.

\begin{tabular}{lcc}
\hline Characteristics & Frequency & Percentage \\
\hline Gravidity & & \\
$1-2$ & 282 & 40.9 \\
$3-4$ & 318 & 46.1 \\
$\geq 5$ & 90 & 13.0 \\
\hline Parity & 134 & \\
0 & 394 & 19.4 \\
$1-2$ & 133 & 57.1 \\
$3-4$ & 29 & 19.3 \\
$\geq 5$ & & 4.2 \\
\hline Ideal number of children & 119 & \\
$5-7$ & 367 & 17.2 \\
3-4 & 204 & 53.2 \\
$0-2$ & & 29.6 \\
\hline Partner desire for a child & 229 & 33.2 \\
Agree & 171 & 24.8 \\
Do not know & 12 & 1.7 \\
Husband wants fewer & 111 & 16.1 \\
Husband wants more & & 64.8 \\
Ever use of FP & 447 & 35.2 \\
Yes & 243 & \\
No & & \\
\hline
\end{tabular}

(67.5\%) resided in urban area and 523 (75.8\%) were currently married. Besides, majority of them are at tertiary education level (290) (42\%) and are government and private employees (257) (37.3\%). Five hundred forty-seven (79.3\%) study participants claim to travel $<40$ minutes to reach the nearest health facility (Table 1).

\subsection{Reproductive and Contraceptive Utilization Character-} istics. Three hundred eighteen (46.1\%) have 3-4 gravidity and $394(57.1 \%)$ have $1-2$ parity, respectively. Besides 367 (53.2\%) have 3-4 ideal numbers of children. Moreover 229 (33.2\%) married participants partners agree on the number of children. In addition 447 (64.8\%) study participants had ever used FP (Table 2).

3.3. Proportion of Unintended Pregnancy. From a total of 690 pregnant mothers 162 (23.5\%) (95\% CI (20.3, 26.8)) participants insured their current pregnancy as unintended; from those $73(10.58 \%)$ are unwanted pregnancies and (the rest) $89(12.9 \%)$ are mistimed pregnancies.

From the mentioned reasons for failure to avoid unwanted and mistimed pregnancy, contraceptive failure (24.66\%) was the major reasons for unwanted pregnancy whereas for mistimed pregnancy not using FP (42\%) takes the highest percentage.

3.4. Factors Associated with Unintended Pregnancy. In multivariable logistic regression being formerly married and never married, estimated time to walk to the nearest health facility $>80$ minutes, gravidity $\geq 5,1-2$ parity, and partner disagreement were significantly associated with unintended pregnancy (Table 3).

\section{Discussion}

Proportion of unintended pregnancy is $23.5 \%$ (95\% CI (20.3, 26.8)), which is in line with the national study conducted in Ethiopia (24\%) [5]. However it is slightly lower than the result reported in the national figure EDHS 2011 which is $29 \%$ [4] and also lower than the studies in different parts of Ethiopia, in Kersa Woreda, eastern Ethiopia, Harar, Hosanna, and Ganji Woreda, West Welega, Oromia which is $27 \%, 34 \%$, and $36.5 \%$, respectively $[16,17,21]$ and study in Tanzania $(50.7 \%)$ [7]. The result might be lower due to the fact that once pregnancy happened there is tendency to be confirmed as intended [22]. In addition the variance might be on account of the difference in sociodemographic and cultural status of the study areas.

The odds of having unintended pregnancy among formerly and never married women are 8.42 and 9.21 times more likely than currently married women. This finding is consistent with the study in Nairobi, Kenya [23]. Women who travel $>80$ minutes to health facility are 3.56 times more likely to report their pregnancy as unintended; this may be due to less supply of family planning service [24]. The finding is in line with study in Kersa Woreda Eastern Ethiopia [16].

Women whose gravidity $\geq 5$ are 3.88 times more likely to have unintended pregnancy than those whose gravidity 1-2, which is supported by other studies [17]. Women having 12 live births were less likely to have unintended pregnancy as compared to their counterparts. This finding is in line with the study in Kersa Woreda eastern Ethiopia and Senegal, which states association of high parity $(7+)$ and $(2+)$ with unintended pregnancy $[16,18]$. Partner desire for child shows significant association with unintended pregnancy. This is consistent with the study conducted in Hosanna town and report in Ganji Woreda, West Welega, Oromia. The possible reason mentioned in those towns and in this area is the difference in men and women interest in number of children and men want more child than women; socioculturally child is seen as wealth in the community $[17,21]$.

\section{Conclusions and Recommendations}

Proportion of unintended pregnancy in the study area was high. Formerly and never married respondents, distance to the nearest health facility $>80$ minutes, $\geq 5$ gravidity, $1-2$ parity, and partner disagreement on desired number of children were significantly associated with the outcome variable. Therefore, high effort needed to be exerted on this target group by counseling, health education, and providing contraceptive service and clinician must consider these factors in maternal care settings. 


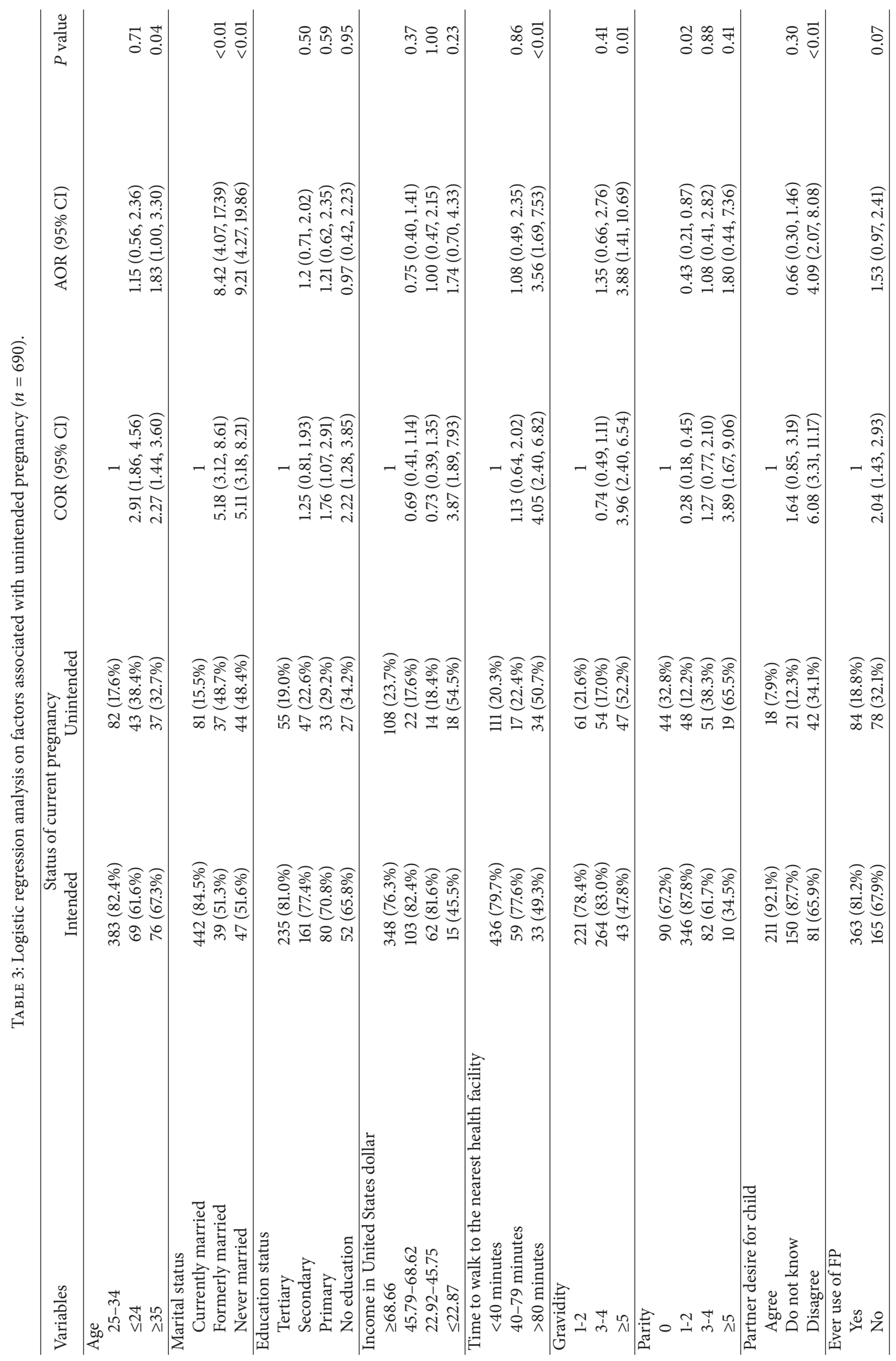




\section{Additional Points}

Limitations of the Study. The result of the study may be underestimated because once pregnancies happen there is a tendency to be confirmed as intended.

\section{Competing Interests}

The authors declared that they have no competing interests.

\section{Authors' Contributions}

Kidest Getu Melese conceived the original idea, is involved in proposal writing, designed the study, and participated in all implementation stages of the project. She analyzed the data and drafted and finalized the writing of the paper. Mignote Hailu Gebrie is involved in proposal writing and participated in all stages of the project implementation and writing of the paper. Martha Berta Badi is involved in proposal writing and participated in all stages of the project implementation and writing of the paper. Wubalem Fekadu Mersha is involved in proposal writing and participated in all stages of the project implementation and writing of the paper. All authors read and approved the final manuscript.

\section{Acknowledgments}

The authors' heartfelt acknowledgment goes to University of Gondar for its financial support and study participants for their time.

\section{References}

[1] "CDC-Unintended Pregnancy Prevention-Reproductive Health," http://www.cdc.gov/reproductivehealth/unintendedpregnancy/.

[2] A. Singh, S. Chalasani, M. A. Koenig, and B. Mahapatra, "The consequences of unintended births for maternal and child health in India," Population Studies, vol. 66, no. 3, pp. 223-239, 2012.

[3] M. Khajehpour, M. Simbar, S. Jannesari, F. Ramezani-Tehrani, and H. A. Majd, "Health status of women with intended and unintended pregnancies," Public Health, vol. 127, no. 1, pp. 5864, 2013.

[4] A. Singh, A. Singh, and S. Thapa, "Adverse consequences of unintended pregnancy for maternal and child health in Nepal," Asia-Pacific Journal of Public Health, vol. 27, no. 2, pp. NP1481NP1491, 2015.

[5] D. Habte, S. Teklu, T. Melese, and M. G. M. D. Magafu, "Correlates of unintended pregnancy in Ethiopia: results from a national survey," PLoS ONE, vol. 8, no. 12, Article ID e82987, 2013.

[6] R. Adhikari, K. Soonthorndhada, and P. Prasartkul, "Correlates of unintended pregnancy among currently pregnant married women in Nepal," BMC International Health and Human Rights, vol. 9, no. 1, article 17, 2009.

[7] A. Exavery, A. M. Kanté, A. Hingora, G. Mbaruku, S. Pemba, and J. F. Phillips, "How mistimed and unwanted pregnancies affect timing of antenatal care initiation in three districts in Tanzania," BMC Pregnancy and Childbirth, vol. 13, article no. 35, 2013.
[8] Y. Dibaba, M. Fantahun, and M. J. Hindin, "The effects of pregnancy intention on the use of antenatal care services: systematic review and meta-analysis," Reproductive Health, vol. 10, no. 1, article 50, 2013.

[9] Y. D. Wado, M. F. Afework, and M. J. Hindin, "Unintended pregnancies and the use of maternal health services in southwestern Ethiopia," BMC International Health and Human Rights, vol. 13, no. 1, article 36, 2013.

[10] R. A. Karim, "Reproductive health, including adolescent reproductive health: Progress and challenges in Asia and the Pacific," Asia-Pacific Population Journal, vol. 24, no. 1, pp. 153-196, 2009.

[11] E. Yanikkerem, S. Ay, and N. Piro, "Planned and unplanned pregnancy: effects on health practice and depression during pregnancy," Journal of Obstetrics and Gynaecology Research, vol. 39, no. 1, pp. 180-187, 2013.

[12] D. Cheng, E. B. Schwarz, E. Douglas, and I. Horon, "Unintended pregnancy and associated maternal preconception, prenatal and postpartum behaviors," Contraception, vol. 79, no. 3, pp. 194198, 2009.

[13] S. Singh and J. E. Darroch, "Adding it up: costs and benefits of contraceptive services," Guttmacher Inst UNFPA, 2012, http:// www.guttmacher.org/pubs/AIU-2012.

[14] S. Singh, G. Sedgh, and R. Hussain, "Unintended pregnancy: worldwide levels, trends, and outcomes," Studies in Family Planning, vol. 41, no. 4, pp. 241-250, 2010.

[15] Ethiopia 2011 Demographic and Health Survey-Key FindingsSR191, http://www.measuredhs.com/pubs/pdf/SR191/SR191.pdf.

[16] N. Kassa, Y. Berhane, and A. Worku, "Predictors of unintended pregnancy in Kersa, Eastern Ethiopia, 2010," Reproductive Health, vol. 9, no. 1, article 1, 2012.

[17] B. Hamdela, A. G/mariam, and T. Tilahun, "Unwanted pregnancy and associated factors among pregnant married women in Hosanna town, Southern Ethiopia," PLoS ONE, vol. 7, no. 6, article e39074, 2012.

[18] C. M. Faye, I. S. Speizer, J. C. Fotso, M. Corroon, and D. Koumtingue, "Unintended pregnancy: magnitude and correlates in six urban sites in Senegal," Reproductive Health, vol. 10, no. 1, article 59, 2013.

[19] Y. Zhou, C. Xiong, J. Xiong et al., "A blind area of family planning services in China: unintended pregnancy among unmarried graduate students," BMC Public Health, vol. 13, no. 1, article 198, 2013.

[20] P. Dixit, F. Ram, and L. K. Dwivedi, "Determinants of unwanted pregnancies in India using matched case-control designs," BMC Pregnancy and Childbirth, vol. 12, article 84, 2012.

[21] F. T. Teshome, A. G. Hailu, and A. N. Teklehaymanot, "Prevalence of unintended pregnancy and associated factors among married pregnant women in Ganji woreda, west Wollega Oromia region, Ethiopia," Science Journal of Public Health, vol. 2, no. 2, pp. 92-101, 2014.

[22] T. Joyce, R. Kaestner, and S. Korenman, "The stability of pregnancy intentions and pregnancy-related maternal behaviors," Maternal and Child Health Journal, vol. 4, no. 3, pp. 171-178, 2000.

[23] L. Ikamari, C. Izugbara, and R. Ochako, "Prevalence and determinants of unintended pregnancy among women in Nairobi, Kenya," BMC Pregnancy and Childbirth, vol. 13, no. 1, article 69, 2013.

[24] A. Sebhatu, "The implementation of Ethiopias Health Extension Program: an overview," 2008, http://www.ppdafrica.org/index .Php/en/publications/documents/139-Ethiop. 


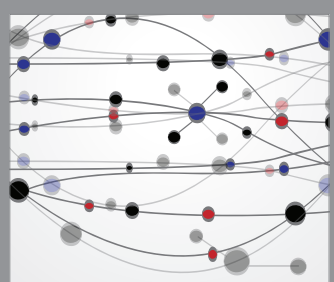

The Scientific World Journal
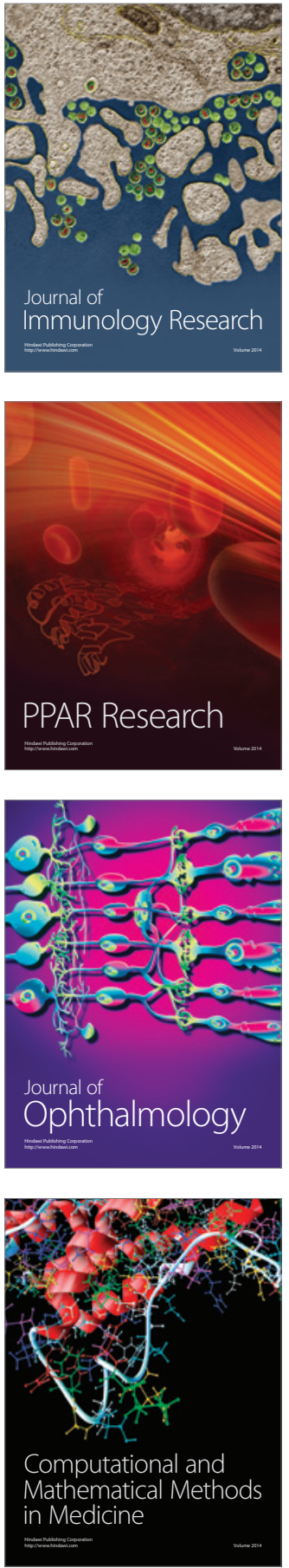

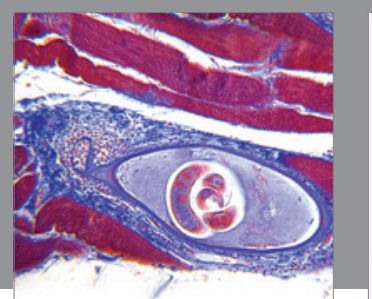

Gastroenterology Research and Practice

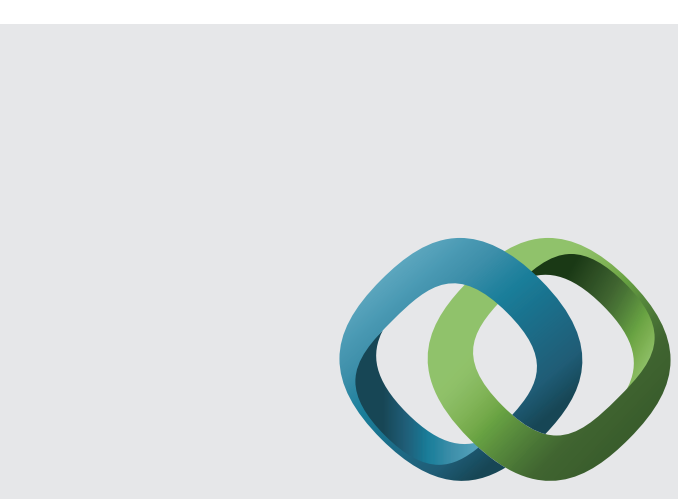

\section{Hindawi}

Submit your manuscripts at

http://www.hindawi.com
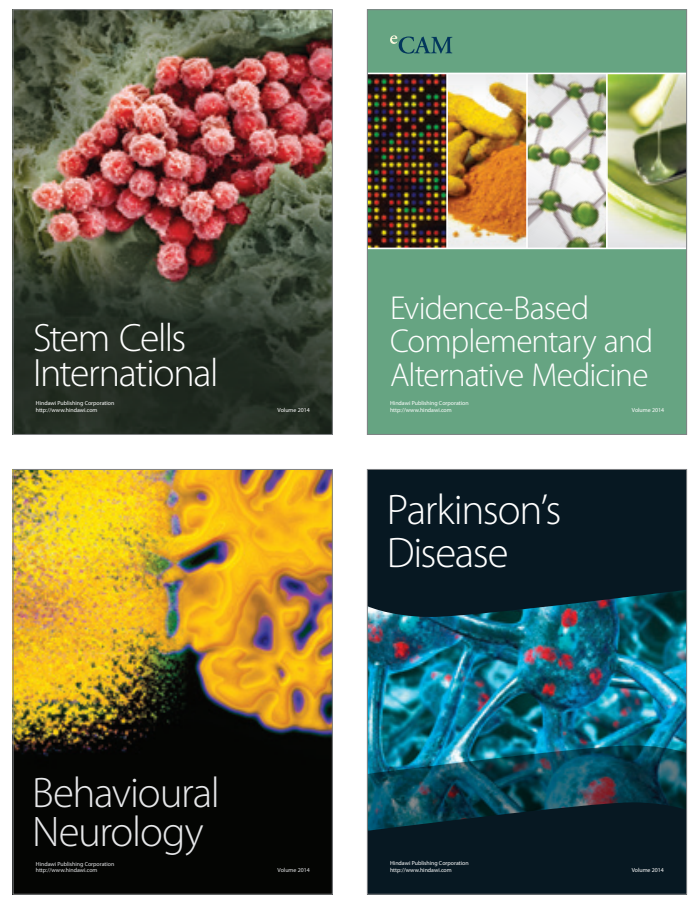
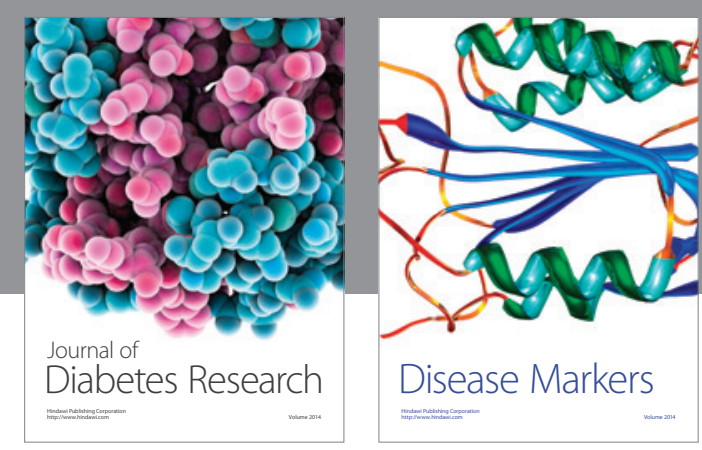

Disease Markers
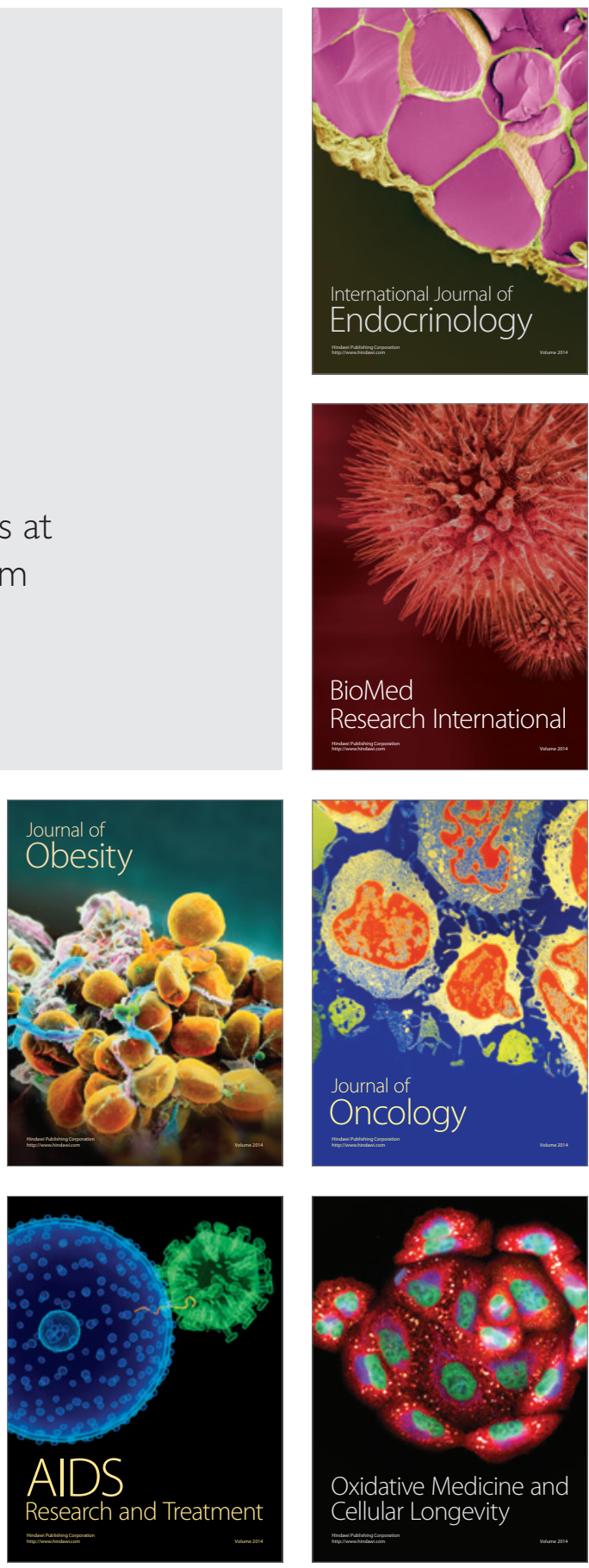